\title{
A Negative Effect of a Contractive Pose is not Evidence for the Positive Effect of an Expansive Pose: Comment on Cuddy, Schultz, and Fosse (2018)
}

\author{
Marcus Credé \\ Iowa State University
}

\begin{abstract}
Cuddy, Schultz and Fosse (2018) present the results of p-curve analyses that are interpreted as providing "clear evidential value for power posing effects". This commentary highlights that the vast majority of the studies included in the p-curve analyses were not designed in a way that could speak to the efficacy of power poses relative to a normal or neutral pose. Further, I discuss how the few studies that were designed to shed light on this issue indicate that any overall effect of physical pose on feelings of power, emotions, affect, and self-evaluations is almost entirely due to the negative effect of a contractive pose and not any positive effect of expansive power poses.
\end{abstract}

Keywords: Power pose, contractive pose, expansive pose, $\mathrm{p}$-curve

Power posing occurs when an individual adopts an expansive physical posture, such as a "wonder woman" pose. An initial examination of the consequences of power posing (Carney, Cuddy \& Yap, 2010) reported that participants who adopted a power pose experienced decreased levels of cortisol, increased levels of testosterone, as well as higher feelings of power, and a higher willingness to take risks relative to participants who had adopted a contractive pose (e.g., slouching). Power posing was subsequently recommended in a very widely viewed TED (e.g., Cuddy, 2012), and a bestselling book (Cuddy, 2015), as a way to improve feelings of power and performance in interviews (see also Cuddy, Wilmuth, Yap, \& Carney, 2015).

The finding that power posing has positive effects on testosterone and risk-taking and negative effects on cortisol could not be successfully replicated by Ranehill, Dreber, Johannesson, Leiberg, and Weber, (2015), whereas the effect on reported feelings of power was replicated. A later p-curve analysis of the accumulated literature on power poses (Simmons \& Simonsohn, 2017) concluded that there was no evidential evidence in support of the claim that power poses had a positive effect, although this analysis excluded any effects that related to feelings of power. A meta-analysis of the effects reported in a series of seven papers published in a special 2017 issue of the journal Comprehensive Results in Social Psychology reported very strong evidence in support of an effect of power posing on feelings of power (see Gronau et al., 2017). More recently, Cuddy, Schultz, and Fosse (2018) presented the results of updated p-curve analyses of the literature on postural feedback and concluded that the accumulated evidence is strongly supportive of the claim that power posing is beneficial for both a) feelings of power and b) emotions, affect, and self-evaluations (EASE variables). Specifically, the authors conclude that their analysis provides "... strong evidential value for postural feedback (i.e., power-posing) effects and particularly robust evidential value for effects on emotional and affective states" (p. 656) and that adopting an expansive pose (i.e., power posing) "leads people to feel more powerful" (p. 662). This

\footnotetext{
${ }^{1}$ Correspondence concerning this article should be sent to Marcus Credé at mcrede@iastate.edu
} 
commentary identifies two broad reasons why these two particular inferences are not warranted.

\section{Feelings of Power}

The claim that power posing results in people feeling more powerful is based on the results of 15 studies, eleven of which were significant (at alpha $=.05$ ) and subsequently included in the $\mathrm{p}$-curve analysis as described by Cuddy et al. (2018). However, ten of these eleven studies (described in Carney, Cuddy, \& Yap, 2010; Garrison, Tang, \& Schmeichel, 2016 ${ }^{1}$; Huang, Galinsky, Gruenfeld, \& Guillory, 2011; Park, Streamer, Huang, \& Galinsky, 2013; Ranehill et al., 2015; Rotella \& Richeson, 2013; Teh et al., 2016) all failed to include a control group (or a baseline measure of feelings of power) and simply compared participants adopting an expansive pose with participants who adopted a contractive pose (e.g., slouching). As a result the results from these studies cannot speak to the benefits of an expansive pose relative to a neutral or natural pose. A finding that participants who adopted an expansive pose report higher average levels of feelings of power than participants who adopted a contractive pose can be the result of a positive effect of expansive poses, a negative effect of contractive poses, or a combination of these two effects. However, the specific claim that individuals should adopt an expansive pose because they have a positive effect relative to an individual's natural pose should not be based on the findings from experiments that failed to compare expansive poses with natural poses. Cuddy et al. did not include the seven studies on power poses as reported in the 2017 special issue of Comprehensive Results in Social Psychology in their updated p-curve analyses but these seven studies also all failed to compare an expansive pose with a neutral pose.

Of the eleven studies that were examined by Cuddy et al. (2018) and that reported a significant effect of posture on feelings of power only the study described by Ceunen, Zaman, Vlaeyen, Dankaerts, and Van Diest (2014) included a control group and it is therefore the only study that can shed any light on whether power poses are likely to benefit individuals relative to a neutral pose. It is therefore worth considering the results of this study more closely.
Ceunen et al. (2014) compare the effect of a slouched sitting pose, neutral sitting pose, and extended (i.e., power pose) sitting posture on (among other variables) feelings of dominance (i.e., power). The authors report on overall effect of posture on feelings of dominance $(\mathrm{F}(2,64=9.57, \mathrm{p}<.001)$ and Cuddy et al. (2018) included this effect in their pcurve analysis for feelings of power. However, the authors also report that feelings of dominance were highest in the neutral sitting position (Mean=5.52, $\mathrm{SD}=1.60$ ), and slouched position (Mean=5.17, $\mathrm{SD}=1.79$ ), and lowest in the power pose condition (Mean=4.24, SD=1.79). In other words, while there was a statistically significant overall effect of posture on feelings of power this effect was in the opposite direction to what is claimed by Cuddy et al. (2018). In other words, the only study that can speak to the value of a power pose relative to a neutral pose for feelings of power finds that a power pose is associated with diminished feelings of power.

\section{Emotion, Affect, and Self-Evaluations (EASE)}

A similar set of problems is also evident for the set of studies that were included in the p-curve analysis of EASE variables. That is, thirteen of sixteen studies reported a significant effect of postural manipulation on EASE variables but ten of these studies (described in Brinol, Petty, \& Wegener, 2009; Kozak, Roberts \& Patterson, 2014; Nair, Sagar, Sollers, Consedine, \& Broadbent, 2015; Peper, Booiman, Lin, \& Harvey, 2016; Riskind, 1983; Riskind, 1984; Teh et al., 2016; Veenstra, Schneider, \& Koole., 2017 [Experiment 2], Welker, Oberleitner, Cain \& Carre, 2013; Wilson \& Peper, 2004) all failed to include either a control group or baseline measurements on the EASE variables. Only three of the thirteen studies were designed in a way that allows an inference to be drawn about the effect of power posing relative to a neutral posture on EASE variables. Each of these three studies is discussed in more detail below.

Zabetipour, Pishghadam, and Ghonsooly, (2015) compare the effect of three poses: a) an ordinary posture, b) an expansive pose, and c) a contractive pose, and find a significant effect of pose on mood $(F[2,42]=13.689, p<.001)$. However, this overall effect is primarily due to the negative effect of the contractive pose (Mean mood $=107.00, S D=24.41$ ) relative to the ordinary posture (Mean=168.33, $\mathrm{SD}=36.85$ ), 
rather than any positive effect of the expansive pose (Mean=160.73, SD=41.48). Indeed, the average mood in the expansive pose condition is lower than in the ordinary pose condition.

Veenstra, Schneider, and Koole (2017, Experiment 1) also compared the effect of three poses: a) a comfortable body position that was treated as the control condition, b) a contractive pose, and c) an expansive pose, and reported a significant effect of posture on the reduction of negative mood over time (mood recovery, $(F[2,223]=5.98, p=.003)$. As was the case for the paper by Zabetipour et al., this overall effect was almost entirely due to the negative effect of the contractive posture. Participants in a contractive pose exhibited a small decrease in negative mood $(d=10)$ while those in the neutral pose condition $(d=.42)$ and expansive pose condition $(d=.28)$ exhibited greater decreases in negative mood. Indeed, Veenstra et al. note (p. 1366) that "Together, these results indicate that adopting a stooped posture resulted in less mood recovery than adopting a straight or control posture".

A somewhat similar effect is also evident in the study described by Rossberg-Gempton and Poole (1993), which has the lowest of all the p-values included in the p-curve analysis. Participants were randomly assigned to either a contractive pose condition or an expansive pose condition and eight different moods were measured both prior to and after the pose manipulation. The authors report a significant posture by emotion interaction $(F[7,140]=1927$, $p<.0001)$ and this effect and the associated $p$-value was included in the $\mathrm{p}$-curve analysis. Precise values (means and standard deviations) are not reported in this paper but Figure 1 (p. 78) of the Rossberg-Gempton and Poole paper indicates that this effect is primarily due to the large increases in negative mood states ("sad", "angry", "disgusted") relative to baseline, and large decreases in positive mood ("happy", "agreeable", "interested") relative to baseline that were reported by participants in the contractive pose condition. The changes reported by participants in the expansive pose condition were low across seven of the eight moods. In other words, a contractive pose had a strong negative effect on mood while the effect for the expansive pose was small.

\section{Conclusion}

The studies reviewed by Cuddy et al. (2018) represent evidential value for an overall effect of posture on reported feelings of power, emotions, affect, and self-evaluations. As such they make a contribution to our broader understanding of sensorimotor feedback, although I echo the concerns of Simons and Simonsohn (2017) that some of these effects may be a function of demand characteristics. However, because of the lack of control groups most of the studies do not represent evidential value that this overall effect of posture is driven by a positive effect of power posing. Indeed, the only four studies that were designed in a way that allowed researchers to compare the effects of contractive poses with the effects of power poses suggest that the overall effect is largely driven by a negative effect of a contractive pose and not by a positive effect of power posing.. The only conclusion that researchers should draw from the existing literature on postural feedback is that contractive poses such as slouching should be avoided.

\section{Open Science Practices}

This commentary includes no data, materials or preregistration to be shared, or any analysis to be reproduced. The full editorial history, including the reviews and a summarized review report is available on the OSF supplementary page.

\section{References}

Brinol, P., Petty, R.E., \& Wagner, B. (2009). Body posture effects on self-evaluation: A selfvalidation approach. European Journal of Social Psychology, 39, 1053-1064. https://doi.org/10.1002/ejsp.607

Carney, D. R., Cuddy, A. J. C., Yap, A. J. (2010). Power posing: Brief nonverbal displays affect neuroendocrine levels and risk tolerance. Psychological Science, 21, 1363-1368. https://doi.org/10.1177/0956797610383437

Ceunen, E., Zaman, J., Vlaeyen, J.W.S., Dankaerts, W., Van Diest, I. (2014). Effect of seated trunk posture on eye blink startle and subjective 
experience: comparing flexion, neutral upright posture, and extension of spine. PLOS One, 9 , e88482.

https://doi.org/10.1371/journal.pone.0088482

Cuddy, A. J. C., Schultz, S. J., \& Fosse, N.E. (2018). Pcurving a more comprehensive body of research on postural feedback reveals clear evidential value for power-posing effect: Reply to Simmons and Simonsohn (2017).

Psychological Science, 29, 656-666. https://doi.org/10.1177/0956797617746749

Cuddy, A.J.C (June 2012). Your body language shapes who you are. [Video file]. Retrieved from

http://www.ted.com/talks/amy_cuddy_your _body_language_shapes_who_you_are

Cuddy, A.J.C. (2015). Presence: Bringing your boldest self to your biggest challenges. Hachette UK.

Cuddy, A.J.C., Wilmuth, C.A., Yap, A.J., \& Carney, D.R. (2015). Preparatory power posing affects nonverbal presence and job interview performance. Journal of Applied Psychology, 100, 1286-1295. https://doi.org/10.1037/a0038543

Garrison, K.E., Tang, D., \& Schmeichel, B.J. (2016). Embodying power: A preregistered replication and extension of the power pose effect. Social Psychological and Personality Science, 7, 623630. https://doi.org/10.1177/1948550616652209

Gronau, Q.F., Van Erp, S., Heck, D.W., Cesario, J., Jonas, K.J., \& Wagenmakers, E.J. (2017). A Bayesian model-averaged meta-analysis of the power pose effect with informed and default priors: the case of felt power. Comprehensive Results in Social Psychology, 2, 123-138. https://doi.org/10.1080/23743603.2017.132676 0

Huang, L., Galinksy, A.D., Gruenfeld, D.H., Guillory, L.E. (2011). Powerful postures versus powerful roles: which is the proximate correlate of thoughts and behavior. Psychological Science, 22, 95-102. https://doi.org/10.1177/0956797610391912

Kozak, M.N., Roberts, T., \& Patterson, K.E. (2014). She stoops to conquer? How posture interacts with self-objectification and status to impact women's affect and performance. Psychology of
Women Quarterly, 38, 414-424. https://doi.org/10.1177/0361684313517865

Nair, S., Sagar, M., Sollers, J., Consedine, N. \& Broadbent, E. (2015). Do slumped and upright postures affect stress responses? A randomized trial. Health Psychology, 34, 632641. https://doi.org/10.1037/hea0000146

Park, L. E., Streamer, L., Huang, L., \& Galinsky, A. D. (2013). Stand tall, but don't put your feet up: Universal and culturally-specific effects of expansive postures on power. Journal of Experimental Social Psychology, 49, 965-971. https://doi.org/10.1016/j.jesp.2013.06.001

Peper, E., Booiman, A., Lin, I.-M., \& Harvey, R. (2016). Increase strength and mood with posture. Biofeedback, 44, 66-72. https://doi.org/10.5298/1081-5937-44.2.04

Ranehill, E., Dreber, A., Johannesson, M., Leiberg, S., Sul, S., \& Weber, R.A. (2015). Assessing the robustness of power posing: No effect on hormones and risk tolerance in a large sample of men and women. Psychological Science, 26, 653-656. https://doi.org/10.1177/0956797614553946

Riskind, J. H. (1984). They stoop to conquer: Guiding and self-regulatory functions of physical posture after success and failure. Journal of Personality and Social Psychology, 47(3), 479493. https://doi.org/10.1037/00223514.47.3.479

Riskind, J.H. (1983). Nonverbal expressions and the accessibility of life experience memories: A congruence hypothesis. Social Cognition, 2, 6286. https://doi.org/10.1521/soco.1983.2.1.62

Rossberg-Genton, I., \& Poole, G.D. (1993). The effect of open and closed postures on pleasant and unpleasant mood. The Arts in Psychotherapy, 20, 75-82. https://doi.org/10.1016/0197-4556(93)90034$\mathrm{Y}$

Rotella, K. N., \& Richeson, J. A. (2013). Body of guilt: Using embodied cognition to mitigate backlash to reminders of personal \& ingroup wrong. Journal of Experimental Social Psychology, 49(4), 643-650. https://doi.org/10.1016/j.jesp.2013.02.013

Simmons, J. P., \& Simonsohn, U. (2017). Power posing:P-curving the evidence. Psychological 
Science, 28, 687-693.

https://doi.org/10.1177/0956797616658563

Teh, P., Lim, W.M., Ahmed, P.K., Chan, A.H.S., Loo, J.M.Y., Cheong, S., \& Yap, W. (2016). Does power posing affect gerontechnology adoption among older adults? Behavior and Information Technology, 36, 33-42.

https://doi.org/10.1080/0144929X.2016.117550 8

Veenstra, L. Schneider, I.K., Koole, S.L. (2017). Embodied mood regulation: the impact of body posture on mood recovery, negative thoughts, and mood-congruent recall, Cognition and Emotion, 31, 1361-1376. https://doi.org/10.1080/02699931.2016.12250 03

Welker, K.M., Oberleitner, D.E., Cain, S., \& Carre, J.M. (2013). Upright and left out: Posture moderates the effects of social exclusion on mood and threats to basic needs. European Journal of Social Psychology, 43, 355-361. https://doi.org/10.1002/ejsp.1944

Wilson, V.E., \& Peper, E. (2004). The effects of upright and slumped postures on the recall of positive and negative thoughts. Applied Psychophysiology and Biofeedback, 29, 189-195. https://doi.org/10.1023/B:APBI.0000039057.3 2963.34

Zabetipour, M., Pishghadam, R., \& Ghonsooly, B. (2015). The impacts of open/closed body positions and postures on learners' moods. Mediterranean Journal of Social Sciences, 6 , 643-655.

https://doi.org/10.5901/mjss.2015.v6n2s1p643 